
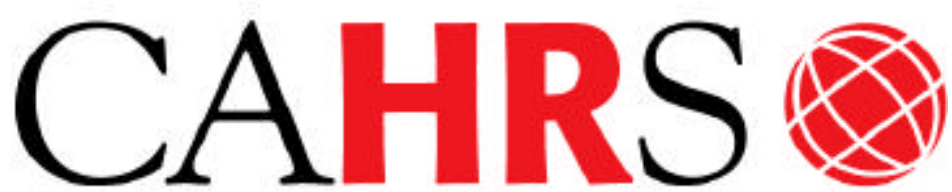

Center for Advanced Human Resource Studies
CAHRS / Cornell University 187 Ives Hall

Ithaca, NY 14853-3901 USA

Tel. 607 255-9358

www.ilr.cornell.edu/CAHRS/

VWRA N GAPER SERIES

\title{
Comparing Line and HR Executives' Perceptions of HR Effectiveness: Services, Roles, and Contributions
}

Patrick M. Wright

Gary C. McMahan

Scott A. Snell

Barry Gerhart

Working Paper 9 8- 29 


\title{
Comparing Line and HR Executives' Perceptions of HR Effectiveness: Services, Roles, and Contributions
}

\author{
Patrick M. Wright \\ School of Industrial and Labor Relations \\ Cornell University \\ Ithaca, NY 14853-3901 \\ Gary C. McMahan \\ Department of Management \\ University of Texas at Arlington \\ Arlington, TX 76019 \\ Scott A. Snell \\ Department of Management and Organization \\ Pennsylvania State University \\ University Park, PA 16802 \\ Barry Gerhart \\ Owen School of Management \\ Vanderbilt University \\ Nashville, TN 37203
}

Working Paper 98-29

http://www.ilr.cornell.edu/cahrs

This paper has not undergone formal review or approval of the faculty of the ILR School. It is intended to make results of Center research available to others interested in preliminary form to encourage discussion and suggestions. 


\begin{abstract}
This study compared HR and line executives' evaluations of the effectiveness of the HR function in terms of its service delivery, roles, and contributions to the firm. Survey responses from $44 \mathrm{HR}$ and 59 line executives from 14 companies indicated that (a) HR executives consistently rated the functions effectiveness higher than did line executives, and (b) the greatest differences were observed on the more important and/or strategic aspects of HR. Implications are discussed.
\end{abstract}

This study was partially funded by a grant from the Society for Human Resource Management Foundation. Interpretations, conclusions, and recommendations, however are solely those of the authors and do not necessarily represent those of the SHRM Foundation. All correspondence regarding this manuscript should be addressed to the first author. 


\section{Comparing Line and HR Executives' Perceptions of HR Effectiveness: Services, Roles, and Contributions}

"The constant worry of all personnel administrators is their inability to prove that they are making a contribution to the enterprise. Their preoccupation is with the search for a "gimmick" that will impress their management associates. Their persistent complaint is that they lack status."

Peter Drucker, The Practice of Management, (1954), p. 205

Nestling warm and sleepy in your company, like the asp in Cleopatra's bosom, is a department whose employees spend $80 \%$ of their time on routine administrative tasks. Nearly every function of this department can be performed more expertly for less by others. Chances are its leaders are unable to describe their contribution to value added except in trendy, unquantifiable and wannabe terms..... am describing your human resource department, and have a modest proposal: Why not blow it up?

Thomas A. Stewart, Fortune, 1/15/96, p. 105

The search for status and respect within the organization has plagued the field of Human Resources (HR) for over 40 years. During the era of downsizing, reengineering, and outsourcing, it became apparent that HR executives' intuitive belief that the services, roles, and contributions of the HR function are critical to firm success, may not be shared by their line colleagues. In the face of calls for blowing up the HR function (Stewart, 1996), HR executives increasingly have become concerned with being able to demonstrate the HR function's value to the firm (Ulrich, 1997).

The challenge of this task is to convince line executives that HR is providing a valueadded contribution to the firm in order to gain equal footing with other functional areas in the decision making process. While a number of techniques, measures, and models have been proposed, it seems that it might first be important to gather actual data on how the HR function is being evaluated by these line colleagues, and to determine if their perceptions are consistent with those of HR executives. By analyzing the level of agreement or disagreement, it may be possible to strategize more effective ways to provide, document, and communicate the valueadded of HR. Thus, the purpose of this study was to explore how both line and HR executives perceived the effectiveness of the HR function. 


\section{Evaluating HR's Contributions}

Attempts to demonstrate the value of $\mathrm{HR}$ have focused in a few areas. First, $\mathrm{HR}$ executives have sought empirical evidence tying HR to firm performance with divergent results. Considerable progress in demonstrating that HR practices can contribute to firm performance has been made as recent research shows significant returns from investments in HR practices themselves (AMJ Special Issue, 1996; Becker \& Gerhart, 1996; Delery \& Doty, 1996; Huselid, 1995, Becker, Huselid, Pickus, \& Spratt 1997). However, less satisfying are a number of studies which have found that the HR function's involvement in strategic planning exhibits no relationship with firm performance (Bennett, Ketchum, \& Schultz, 1998; Wright, McMahan, McCormick, \& Sherman, 1998). While observing a relationship between an $\mathrm{HR}$ variable and firm performance is quite valuable, this research has failed to rule out a number of competing causal hypotheses (Delery, in press; Ferris, Harrell-Cook \& Kaplan, in press; Gerhart, in press)

A second approach has been to demonstrate the value of $\mathrm{HR}$ through theoretical modeling. For example, Wright, McMahan and McWilliams (1994) used the resource-based view of the firm to analyze how HR can provide human resources that are valuable, rare, inimitable, and non-substitutable, thus fulfilling the criteria of a source of sustainable competitive advantage. Heskett, Sasser, and Schlesinger (1997) described the Service-Profit chain which highlights the importance of people (and, consequently, HR) in generating profits. Yeung and Berman (1997) provide another model showing how HR practices contribute to employee satisfaction and organizational capability, which are then related to customer and shareholder satisfaction. Boudreau and Ramstad (1997) similarly discuss the relationships among what HR does (activities), what HR Makes Happen (attitudes, behavior, capability) and Business Success (customer value added, financial performance). While these models provide extensive theoretical rationale for the value-added of $\mathrm{HR}$, they only describe the potential, rather than observed value.

A third approach is to use actual HR metrics as a means of showing where the HR functions stands in performing its tasks relative to either other firms or its own past performance on these metrics. For example, Fitz-Enz $(1980,1984,1990)$ at the Saratoga Institute has done extensive work in gathering efficiency indicators for a large number of HR activities. While models are quite useful for both internal analyses of areas of potential improvement in service delivery and documentation of actual improvements, they may not provide convincing evidence of any actual value added to line executives.

Finally, one could assess HR effectiveness through surveying its customers. For example, Tsui (1987) examined how managers and supervisors, line executives, and human resource managers and executives rated the importance and effectiveness of the HR function. 
Ulrich (1997) has suggested conducting an HR Audit as part of a balanced scorecard approach to evaluating the effectiveness of the HR function. Balanced scorecards assess performance with regard to the three major organizational stakeholders: Investors, customers, and employees. The HR audit can assess the practices, professionals, or department/function. One aspect of this audit is the customer value survey, where employees as user/customers of the HR programs and practices, indicate their evaluations of the value of these practices. Ulrich notes that one weakness of such an approach is that while employees may know what they want, they may not know what is best for the firm.

However, this problem is alleviated if the survey is conducted among top line executives. These executives may be the best source of evaluative information for a number of reasons. First, they are users of the services both as individuals who are subject to them, and as managers who have a vested interest in these services/practices having the maximal positive impact on employees. Second, they have more extensive knowledge of what might be best for the firm, and are in a unique position to evaluate the tradeoffs between services that might be desired by employees but would put the firm at financial disadvantage. In fact, these individuals are in the ideal position to make decisions regarding how to balance the desires of and returns to shareholders, customers, and employees. ${ }^{1}$ Finally, while employees are an important customer group, ultimately, for the reasons cited above, top line executives serve as HR's most important customer. Thus, we approached evaluating the effectiveness of the HR function by surveying the top line and HR executives within our sample of firms.

\section{Evaluating HR: Services, Roles, and Contributions}

The previous discussion pointed to the value of attempting to evaluate HR via a high level customer survey. However, one must next decide what aspects of the function to assess. Ulrich (1997) noted that the HR audit could evaluate the HR practices, professionals, and/or the department itself. Given the nature of our sample, we decided to evaluate three aspects of HR: Services, roles, and contributions.

One major aspect of $H R$ is the delivery of $H R$ services (or practices) such as staffing/succession planning systems, compensation systems, training and development systems. These systems form the main architecture of the HR system and consist of the practices through which the firm seeks to create a skilled, motivated, and committed workforce.

For this reason we went beyond evaluating just the effectiveness of HR with regard to these services. Given the current talent wars (Fishman, 1998) and the increased recognition that people can be a source of sustainable competitive advantage (Barney \& Wright, 1998; Pfeffer, 1998; Ulrich, 1998), we wanted to assess the extent to which executives thought that the various HR services were important to their firm's competitive advantage. Thus, with regard to each of 
the HR services, we assessed both the importance of the service and HR's effectiveness in delivery.

In addition to the specific HR services, an evaluation of HR's effectiveness in performing various roles. A number of researchers have sought to classify the various roles that HR plays (e.g., Foulkes \& Morgan, 1977). Most recently, Ulrich (1998) has proposed that HR plays 4 basic roles. "Management of Strategic Human Resources" consists of aligning HR strategies and practices with the strategic needs of the business. "Management of Firm Infrastructure" deals with the delivery of efficient HR processes such as staffing, training, appraisal, and reward systems. "Management of Employee Contribution" concerns keeping close tabs on employees needs and problems and these needs are met and problems are solved. "Management of Transformation and Change" refers to HR's role in changing both the culture of the firm and the processes used within the firm.

In this study we broke down the roles in different ways, but ones which capture the essence of the roles proposed by Ulrich (1998). The "Strategic Partner" role focuses on HR's participation in and influence over the formulation of strategy. The "Tailoring Practices" role highlighted the role of HR in strategy implementation. It deals with tailoring HR practices to support the business strategy once it is formulated. "Providing HR Services" encompasses HR's role in providing the basic services discussed in the HR Services discussed above. "Providing Change Consulting" refers to HR's role in helping line executives to effectively manage cultural and organizational change. Finally, "Developing Organization Skills and Capabilities" deals with HR's role in identifying and/or developing critical organizational core competencies or capabilities.

The last aspect to HR we chose to assess in this study was its contributions, and this served as more of an overall evaluation of the function. The HR contributions component sought to evaluate how executives felt the HR function was being run and how it was contributing to the firm on different dimensions. For example, the executives rated how HR contributed to the firm's competitive position, bottom line, core competence, and human capital.

In this study we sought to answer the following questions:

Research Question 1: How important do line and HR executives think HR services are to the firm's competitive advantage?

Research Question 2: How effective do line and HR executives think the HR function is in terms of delivering services, fulfilling its various roles, and contributing to the firm?

Research Question 3: Are there differences between HR and line executives in their evaluations of the HR function along these dimensions? 


\section{Method}

The survey results were part of a larger in depth study of how firms use people as a source of competitive advantage and the role of the HR function in doing so. At least two members of the research team visited each of 14 large U.S. firms and spent one to two days on site interviewing the top HR (VP and his/her direct reports) and line (all corporate VP's or VP/GM's of a strategic business unit) executives. The interview lasted between 30 and 60 minutes. At the end of the interview we distributed a survey and asked the interviewees to complete it and mail it back in a self-addressed postage paid envelope. The HR survey differed from the line survey only in the addition of some scales regarding the integration of HR practices. However, the items reported here were identical across the two surveys.

The 14 firms in the sample were all large (mean number of employees was approximately 46,000; median approximately 42,000) and represented a variety of industries including banking, energy, processed food, insurance, computers, food service, transportation, chemicals, and pharmaceuticals. Twelve of the firms were publicly traded, and on average were in the top quartile of their industries in terms of revenues, market share, and profitability. Two of the firms are on the Fortune 1998 "100 Best Companies to Work For" list, and 5 of the firms ranked in the top 100 on the Fortune's 1997 "Most Admired Companies" list.

\section{Measures}

HR Services. HR service delivery consisted of 15 items displayed in Appendix A. These items described the services delivered by the HR function such as "Maintaining an equitable compensation system which controls costs while ensuring that top performers are retained," "Maintaining performance-based incentives to motivate individuals to focus on achieving strategic goals," and "Maintaining effective staffing systems and succession plans to ensure a steady supply of managerial talent."

Respondents were to respond to each of the items on two different scales. First, they were to indicate the relative importance of each of the HR functions in terms of their importance in "maintaining and/or improving this organization's competitive position." Second, they were asked to rate the "current performance" of the HR department for each of the functions. Both ratings were made on 1 (Very Unimportant/Ineffective) to 7 (Very Important/Effective) scales.

HR Roles. HR roles were those assessed by McMahan, Mohrman, and Lawler (1996) in their scale. Respondents were asked to rate the effectiveness of the HR function in terms of the roles "Providing HR Services," "Providing Change Consulting Services," "Being a Business Partner," "Developing Organization Skills and Capabilities," and "Tailoring Practices to Fit Business Needs." These roles were assessed on a 1 (Not Meeting Needs) to 10 (All Needs Met) scale. 
HR Contributions. HR contributions were assessed by asking respondents to rate their agreement with 10 statements regarding HR's contribution using a 1 (Not at All) to 7 (To a Great Extent) scale. The items are displayed in Appendix A, but sample items include "This department has helped to enhance the firm's competitive position," and "This department contributes to building and/or maintaining the firm's core competence."

\section{Results}

The basic research questions dealt with the rated level of effectiveness of the HR function and differences between $\mathrm{HR}$ and line executives in rated effectiveness. Figures 1-4 illustrate the actual ratings which assess the level of effectiveness. We chose to conduct a series of t-tests to assess the differences between line and HR executives in these ratings. In addition, we used correlational analyses to look at agreement in relative ratings which are discussed below.

With regard to the HR services, as can be seen in Figure 1, there were few significant differences between line and HR executives in the rated importance of the various services. In fact, of the 5 observed significant differences, line executives rated the services as more important than HR executives on 4 of them (Compensation, incentive, user friendly benefits, and legal issues). In addition, correlating the mean ratings from each group across items resulted in a correlation of .77 . These results are quite promising in two ways. First, they demonstrate that the line executives view a number of HR activities as being critical to the firm's success. Second, they indicate that HR and line executives tend to agree on both the actual importance and relative importance of the various HR services.

Only a few significant differences between responses from line and HR executives were observed on the effectiveness ratings. HR executives rated HR's effectiveness significantly higher on 5 (staffing, training, employee commitment, HR initiatives, and responsiveness) items and higher (although not significantly) on another 9 of the other 10. A significant difference between line and HR executives existed in the average ratings across the whole set of services. On the other hand, the correlation between the average ratings of line and HR across the items was .89. Thus, these results seem to indicate that HR executives provide higher actual ratings overall, but agree considerably with regard to the relative effectiveness of $\mathrm{HR}$ in providing a variety of $H R$ services. 


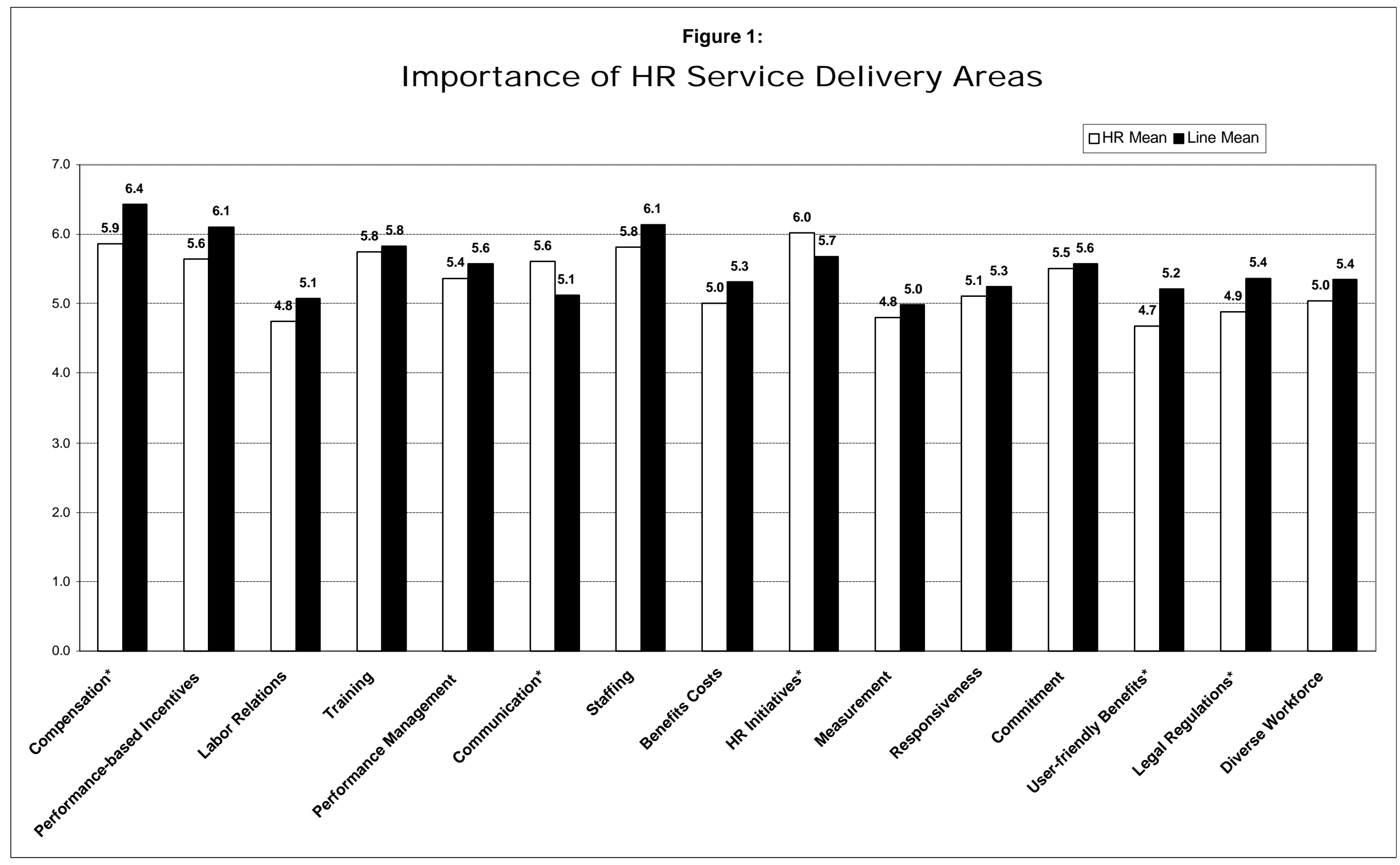




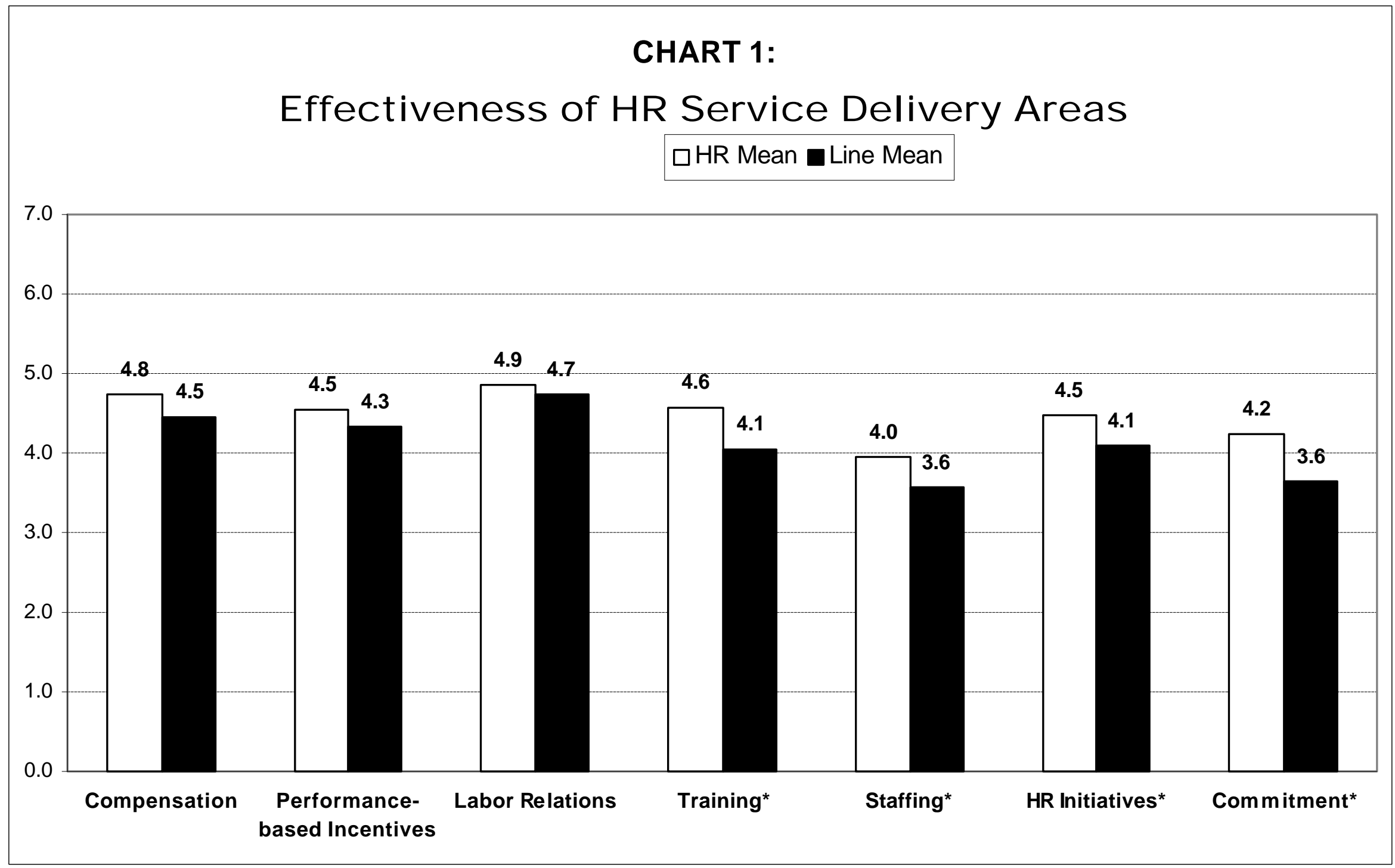


Finally, we noticed a trend for the activities deemed to be most important to also be those on which HR was deemed to be least effective among both groups. Thus, we correlated the mean importance and effectiveness ratings across the various items. We found correlations of .19 and -.21 among the line and HR executives, respectively. This indicates that both line and $\mathrm{HR}$ executives perceive HR as being more effective at delivering the less important services, and vice versa.

As can be seen in Figure 3, HR and line executives also differ with regard to their perceptions of the extent to which the HR function is adequately fulfilling its various roles. Again, the results indicate consensus regarding the relative effectiveness, but divergence regarding the absolute effectiveness across these roles. Line and HR executives agreed with regard to what role HR is best fulfilling (HR Services) and least fulfilling (Change Consulting). However, significant differences were observed for all five roles, with HR executives giving between .8 and 1.6 scale points higher ratings on these items relative to the line executives.

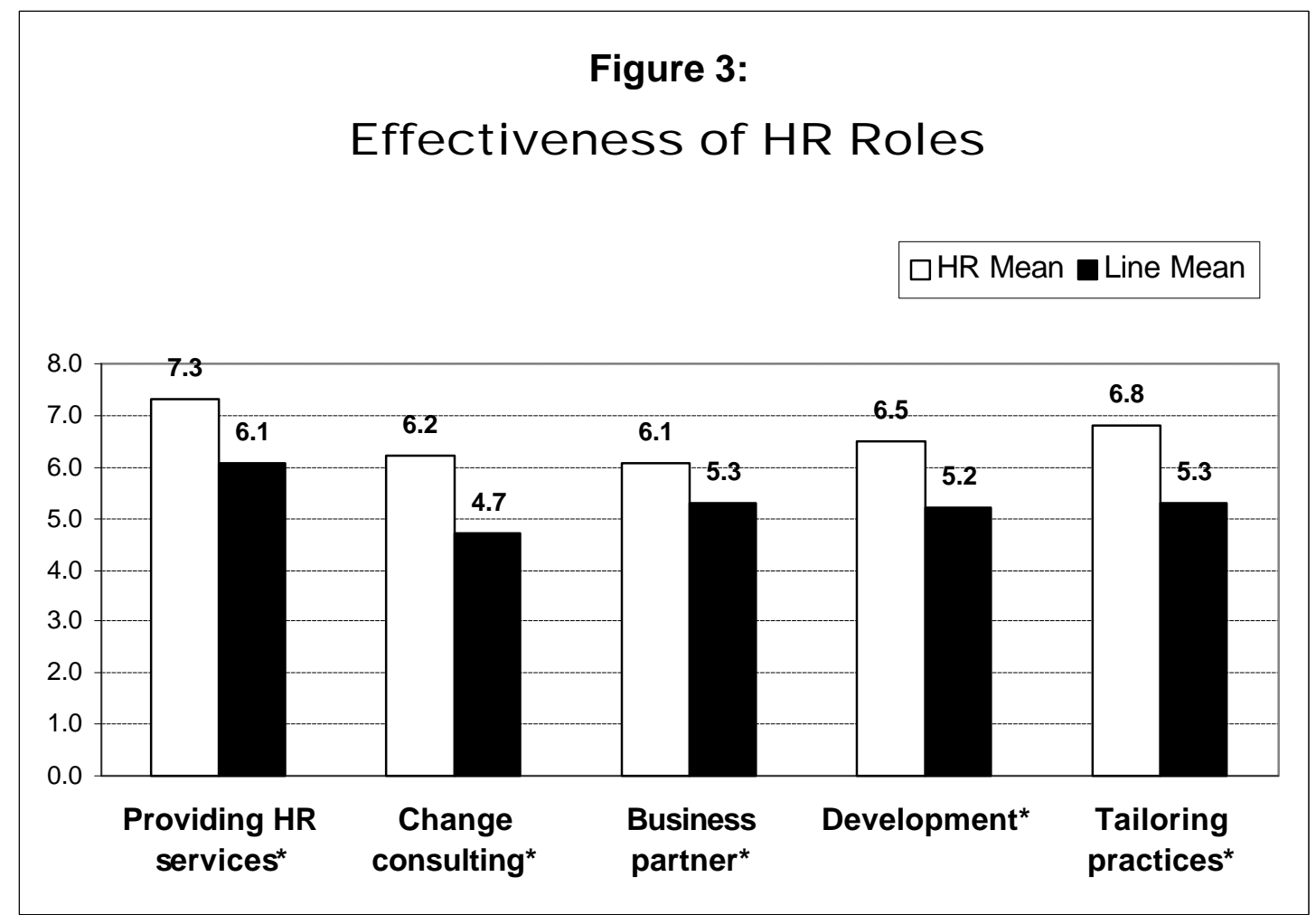

Finally, and most troubling, Figure 4 illustrates that HR and line executives also differ in their ratings of HR's contributions to the success of the firm. In this case, there was little agreement regarding either the relative effectiveness or the absolute effectiveness. Regarding the absolute levels of effectiveness, HR executives gave significantly higher ratings than did line 
executives on 7 of the 10 items (the exceptions being "providing useful information," "providing a coordinated set of practices," and "practices that support the business plan.") In addition, the greatest gaps were observed on the three most important firm performance criteria: Enhancing competitive position (1.2 scale points), providing a value-added contribution (.9 scale points), and building core competence (.6 scale points). Finally, regarding the relative agreement, HR executives gave the highest effectiveness ratings on the items of value added contribution, enhancing competitive position, and responsive to customer needs (all at 5.0 after rounding), while the first two items received the two of the three lowest ratings (3.8 and 4.1$)$ from line executives.

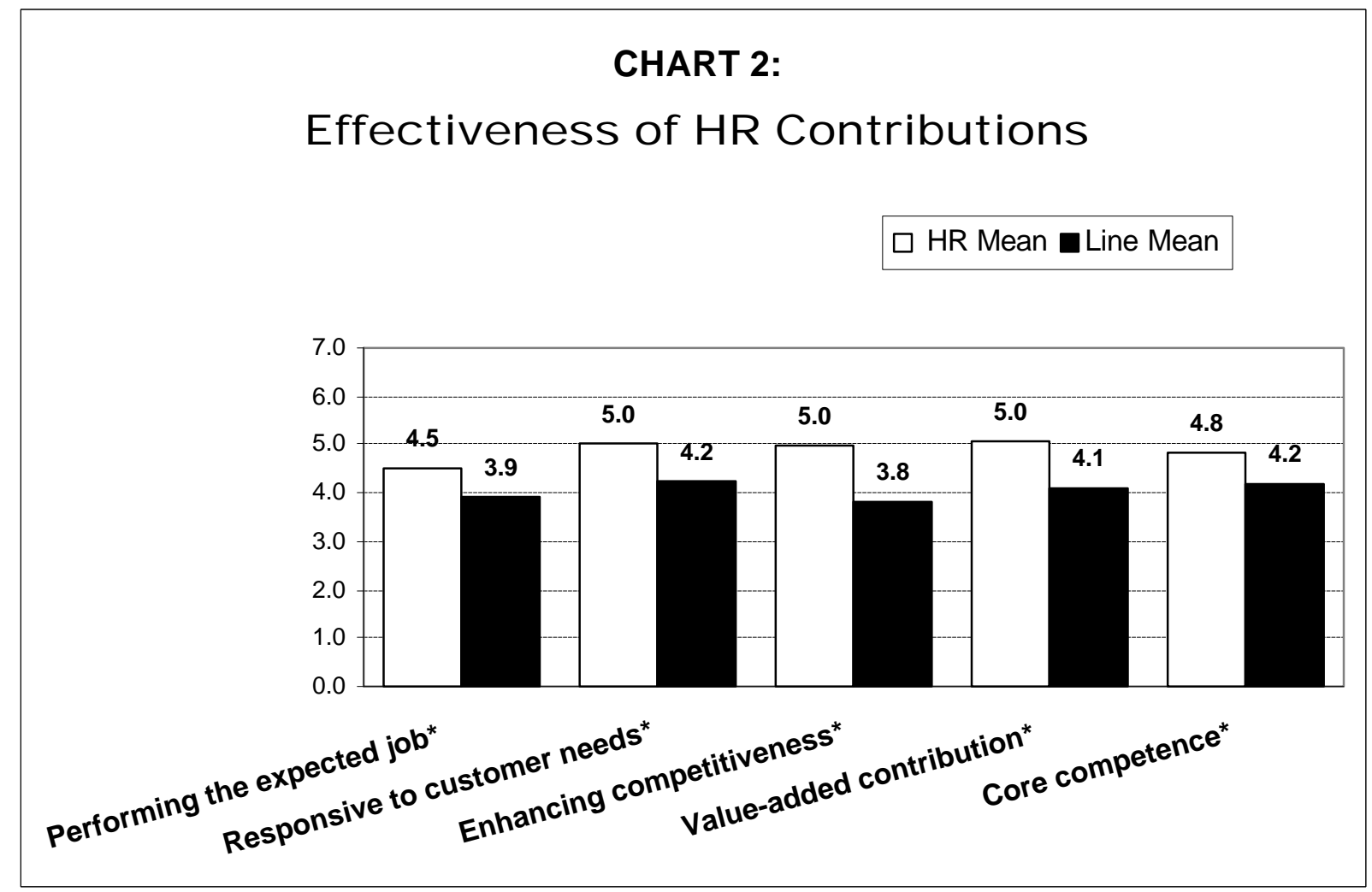

\section{Discussion}

In light of both the increasing importance of a firm's human resources in today's competitive environment and recent calls for "blowing up" the HR function, we sought to examine how line and HR executives viewed the importance and effectiveness of the HR function. Our study reveals some interesting insights regarding the perceived effectiveness of HR within our set of firms. While the results may at first glance, seem disheartening for HR executives, we 
believe that they are quite promising. We discuss both the positive and negative implications of the results below.

On the positive side, first, our study demonstrates that top line executives believe that a number of HR activities are critical to the firm's competitive advantage. Line executives gave average importance ratings of over 6 on a 7-point scale to the equitable compensation system, performance-based incentives, and staffing/succession planning system items. This indicates that they increasingly believe that the attraction, selection, retention, and motivation of employees (particularly managerial talent) are critical to their firm's future success, and that the effective delivery of services provided by HR are integral to the firm's competitive advantage.

In addition, the high levels of agreement between line and HR executives regarding the relative importance and effectiveness of the various $\mathrm{HR}$ services indicates that HR executives seem well aware of where they should be devoting effort. They share with line executives the beliefs regarding both what are the most important HR services and what are the areas of HR service delivery in greatest need of improvement. These quantitative results, along with the interviews we conducted reveal that $\mathrm{HR}$ executives are focusing considerable resources toward developing and/or improving systems aimed at the attraction, motivation, and retention of top performers.

On the somewhat negative side, while line executives see HR services as important and agree with HR executives regarding the relative importance and effectiveness of these services, there seems to be less agreement regarding the absolute effectiveness of the function in delivering HR services. We observed 5 significant differences between HR and line executives across the 15 items. In addition, the overall mean across services was significantly higher for $\mathrm{HR}$ relative to the line executives. Even more problematic is the fact that the items on which significant differences were observed were the ones that dealt with the issues of major import, i.e., the attraction, development, and retention of people (staffing, training, and commitment) and HR's strategic involvement (HR initiatives, responsiveness). Thus, it appears that line executives do not evaluate the performance of the HR function as being as effective as do HR executives.

The results with regard to roles elicit considerable concern as well. In this case, all five roles saw line executives giving significantly lower ratings than HR executives. The good news is that the highest ratings for line executives came on the "Providing HR Services" role, results somewhat consistent with those discussed above. However, over a full scale point difference existed on all of the other items, each of which dealt with the more modern strategic responsibility of HR (Ulrich, 1998). Thus, it appears that line executives seem to view HR as being best at providing basic HR services, but are not quite as impressed with their effectiveness in contributing to the business. 
In fact, the HR Contributions results support this interpretation. HR executives gave significantly higher ratings than line executives on 7 of the 10 items as well as across the summed scale. Additionally, the largest differences between the two groups were on ratings regarding HR's contributions to the firm's competitiveness and its value-added contribution. Less difference was observed on items such as "providing useful information," "providing a coordinated set of HR practices" and "providing practices that support the business plan."

In sum, the results of this study seem to provide support for the notion that HR executives and line executives differ somewhat in their perceptions of the effectiveness of the HR function. More importantly, the differences are greatest regarding HR's effectiveness in playing a strategic role that provides a value-added contribution to the firm. However, these results should not elicit despair, but rather analysis and action. The fact that line executives give lower ratings than HR executives may be due to one or any combination of four factors, and these are discussed below.

First, the most obvious explanation could be that the HR function simply is not delivering on the services, roles, and contributions expected. Few would argue that this is not at least partially true in their organization---there is always room for improvement. The implication of this factor is to focus on improving the skills of HR employees and improving the delivery or HR services. All of the firms in our study indicated that this was a major emphasis within their HR function. In fact, the firms in our sample were interested in participating in this study because all were well into efforts to transform their HR functions to be more strategically focused, and while they recognized that they had room to improve, they felt that they were farther along than most firms.

Second, the differences may be symptomatic of the traditional line-staff conflict. Line executives seldom view staff functions as having as critical a relationship to firm success as the line function. In addition, our interviews with the line executives indicted that some were not thoroughly familiar with all of the activities in which HR was engaged, nor all of the ways in which it was contributing. Given this, it is not surprising that they would have a tendency toward evaluating any staff function (e.g., accounting as well as HR) as not being overly effective. One would expect that were the data to have been with regard to the accounting function, we would observe similar (if not worse) results.

To the extent that this is causing differences in perceptions of effectiveness, it implies that HR executives need to do a better job of internally marketing the activities of HR, and demonstrating their contributions to the firm's success. At the cynical end of this marketing recommendation was one HR executive who said "When line executives don't understand the importance of what we provide, I want to suggest that our function just stop working on anything for one day and see how the organization runs." A more positive approach might be to invest in 
the development of some metrics to tie HR activities to the value creation process, and to ensure that performance on these metrics becomes regular feedback to line executives.

Third, it is important to note that often HR services or programs fail to meet optimum performance not because the systems developed by HR are poor, but because line managers fail to implement these systems effectively. In fact one line executive in our sample pointed out that line executives in his organization criticized the compensation system and blamed it on HR, when in reality the problem was line executives reluctance or failure to implement it properly (i.e., to make the tough calls on variations in individual bonuses). This may stem from a fundamental attribution error. Attribution theory posits and research has supported that individuals tend to attribute success to themselves or internal causes and failure to others or external causes (Weiner, 1995). Thus, it is entirely possible that when line executives fail to properly implement HR systems, they attribute the failure to the HR system, rather than to their own efforts. To the extent that this is causing these observed differences, it implies that HR needs to devote more effort to working with line executives through influence, training, and communication to help them effectively implement the systems developed by the HR function.

Fourth, these results may stem from line executives lack of ownership over HR services if they are not involved in their design. "Buy-in" from executives increases to the extent that they participate in both the development and implementation of a number of HR services. Our results indicate that line executives rate the highest importance on activities in which they are involved in the delivery of the actual practice (e.g., staffing, performance management, etc.), but also rate these a low in effectiveness. Their participation in the delivery may raise their standards, or cause them to zero in on flaws and weaknesses that stem from poor or inadequate design. Thus, involving them in the design may be one way of ensuring that they are satisfied with the practice on the delivery end. For this reason, firms such as Halliburton Energy Services have created oversight committees made up of a number of line executives to have input into the design and delivery of major HR services such as training and development. 


\section{Conclusion}

Our study examined the importance and effectiveness of HR from the viewpoints of both top level line and HR executives. The results indicate that both line and HR executives recognize the potential importance of HR activities to the firm's competitive advantage, and that both groups agree regarding HR's strengths and weaknesses in delivering those services. However, the results also point to the fact that line executives do not give nearly as high marks as HR executives do when it comes to evaluating HR's effectiveness.

These results should not send HR executives into a state of depression, but, rather, be used as the basis for action plans. Given that line executives recognize the potential importance of $\mathrm{HR}$, the key issue is whether or not HR functions can either more effectively deliver on the services, roles and contributions, or more effectively demonstrate and communicate their already existing effectiveness in these areas. This is a challenge that while difficult, is certainly attainable in our field. However, in light of both the historical and recent criticisms of HR noted at the outset and the results we observed, the time for action is now. 


\section{Endnotes}

1. We do not mean to argue that top line executives always make good decisions regarding theses tradeoffs, as in fact, often they make terrible ones. However, they have ultimate responsibility for these decisions, and are in a position to make these decisions. 


\section{Appendix A}

\section{HR Services}

1. Maintaining an equitable compensation system which controls costs while ensuring that top performers are retained.

2. Maintaining performance-based incentives to motivate individuals to focus on achieving strategic goals.

3. Providing labor relations and preventative labor support to business partners and front line managers.

4. Providing training and development programs to enable front line managers to maximize their performance potential.

5. Providing performance management programs to develop and motivate business partners and front line managers.

6. Communicating and marketing key business and human resource initiatives to business partners and front line managers.

7. Maintaining effective staffing systems and succession plans to ensure a steady supply of managerial talent.

8. Controlling benefit costs, particularly health care and sick leave.

9. Developing HR initiatives that contribute to achieving current and future business goals.

10. Tracking important measures and trends (e.g., productivity, turnover, sick leave) to identify potential problem areas.

11. Developing HR initiatives to respond to potential problem areas as noted above.

12. Developing initiatives that help build employee commitment.

13. Maintaining employee/user friendly benefits administration programs.

14. Maintaining programs and providing support to business partners and front line managers to ensure compliance with legal regulations (OSHA, EEO, etc.)

15. Developing initiatives to exploit the value of a diverse workforce.

\section{HR Roles}

1. Providing HR Services

2. Providing Change Consulting

3. Being a Business Partner

4. Developing Organization Skills and Capabilities

5. Tailoring Practices to Fit Business Needs

\section{HR Contributions}

1. The HR department is performing its job the way I would like it to be performed.

2. This department is very responsive to meeting customer (front line managers and employees) needs.

3. This department provides me with useful and timely information regarding HR issues.

4. This department has helped to enhance the firm's competitive position.

5. This department provides value-added contributions to the firm's bottom line.

6. This department contributes to building and/or maintaining the firm's core competence.

7. This department contributes to building the firm's human capital (employees/managers) as a source of competitive advantage.

8. The policies, practices, and procedures coming from the HR department help front-line business partners in their jobs.

9. The HR department has developed a well-coordinated set of policies, practices, and procedures.

10. The HR policies, practices, and procedures help support the firm's business plan. 


\section{References}

Academy of Management Journal (1996), Special Research Forum: Human Resource Management and Organizational Performance. 39, 4, 779-985.

Barney, J., \& Wright, P. (1998). On becoming a strategic partner: The role of Human Resources in gaining competitive advantage. Human Resource Management, $\underline{37}, 1,31-46$.

Becker, B., \& Gerhart, B. (1996). The impact of human resource management on organizational performance: progress and prospect. Academy of Management Journal, 39, 4, 779-801.

Becker, B., Huselid, M., Pickus, P., \& Spratt, M. (1997). HR as a source of shareholder value: Research and recommendations. Human Resource Management, $\underline{36}, 1,39-48$.

Bennett, N., Ketchen, D., \& Schultz, E. (1998). An examination of factors associated with the integration of human resource management and strategic decision making. Human

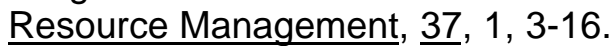

Boudreau, J., \& Ramstad, P. Measuring intellectual capital: Learning from financial history.

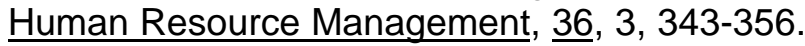

Delery, J. (In press). Issues of fit in strategic human resource management: Implications for research. Human Resource Management Review.

Delery, J.E. \& Doty, D.H. 1996. Theoretical frameworks in strategic human resource management: Universalistic, contingency, and configurational perspectives. Academy of Management Journal, 39: 802-835.

Ferris, G., Harrell-Cook, G. \& Kaplan, D. (In press). Human resource management and organizational performance: Theory and research challenges. Human Resource Management Review.

Fishman, C. (August, 1998). The war for talent. Fast Company, 104-111.

Fitz-enz, J. (1980). Quantifying the human resources function. Personnel, March-April, 41-52.

Fitz-enz, J. (1984). How to measure human resources management, New York, NY: McGrawHill.

Fitz-enz (1990). Human value management: The value-adding human resource management strategy for the 1990's, San Francisco, CA: Jossey-Bass.

Foulkes, F. \& Morgan, H. (1977). Organizing and staffing the personnel function. Harvard Business Review, May-June, 1977.

Gerhart, B. (In press). Human resource management and firm performance. Measurement issues and their effect on causal and policy implications. In P. Wright, L. Dyer, J. Boudreau, and G. Milkovich (eds.) Research in Personnel and Human Resource Management, Supplement A.

Heskett, J., Sasser, E., \& Schlesinger, L. (1997). The Service - Profit Chain, New York, NY: Free Press. 
Huselid, M.A. 1995. The impact of human resource management practices on turnover, productivity, and corporate financial performance. Academy of Management Journal, 38: 635-672.

McMahan, G. Mohrman, S., \& Lawler, E. (1996). The current practice of the Human resources function. Human Resource Planning, $\underline{19}$, 4, 11-13.

Stewart, T., (Jan. 15, 1996). Taking on the last bureaucracy. Fortune, p. 105.

Tsui, A. (1987). Defining the activities and effectiveness of the human resource department: A multiple constituency approach. Human Resource Management, $\underline{6}$, 1, 35-69.

Ulrich, D. (1997). Measuring Human resources: An overview of practice and a prescription for results. Human Resource Management, $\underline{36}$, 3, 303-320.

Ulrich, D. (1998). Human Resource Champions. Boston, MA: Harvard Business School Press.

Weiner, B. (1995). Attribution theory in organizational behavior: A relationship of mutual benefit. In M.J. Martinko (ed.), Attribution Theory: An Organizational Perspective. St. Lucie Press, Delray Beach, FL, pp. 3-6.

Wright, P.M., McMahan, G.C. \& McWilliams, A. 1994. Human resources and sustained competitive advantage: A resource-based perspective. International Journal of Human Resource Management, 5(2): 301-326.

Wright, P.M., McMahan, G.C., Snell, S.A., \& Gerhart, B. 1997. Strategic Human Resource Management: Building Human Capital and Organizational Capability, Technical report.

Wright, P., McMahan, G., McCormick, B., and Sherman, W. (1998). Strategy, core competence, and $\mathrm{HR}$ involvement as determinants of HR effectiveness and refinery performance. Human Resource Management, $37,1,17-30$.

Yeung, A. \& Berman, R. (1997). Adding value through human resources: Reorienting human resource measurement to drive business performance. Human Resource Management, 트, 3, 321-336. 